\title{
Resistance to Crown and Root Rot Caused by Phytophthora capsici in a Tomato Advanced Backcross of Solanum habrochaites and Solanum lycopersicum
}

L. M. Quesada-Ocampo, Department of Plant Pathology, North Carolina State University, Raleigh 27695; A. M. Vargas and R. P. Naegele, Department of Plant, Soil and Microbial Sciences, Michigan State University, East Lansing 48824; D. M. Francis, Department of Horticulture and Crop Science, Ohio Agricultural Research and Development Center, Wooster 44691; and M. K. Hausbeck, Department of Plant, Soil and Microbial Sciences, Michigan State University

\begin{abstract}
Quesada-Ocampo, L. M., Vargas, A. M., Naegele, R. P., Francis, D. M., and Hausbeck, M. K. 2016. Resistance to crown and root rot caused by Phytophthora capsici in a tomato advanced backcross of Solanum habrochaites and Solanum lycopersicum. Plant Dis. 100:829-835.

Phytophthora capsici causes devastating disease on many vegetable crops, including tomato and other solanaceous species. Solanum habrochaites accession LA407, a wild relative of cultivated tomato, has shown complete resistance to four $P$. capsici isolates from Michigan cucurbitaceous and solanaceous crops in a previous study. Greenhouse experiments were conducted to evaluate 62 lines of a tomato inbred backcross population between LA407 and the cultivated tomato 'Hunt 100' and 'Peto 95-43' for resistance to two highly virulent $P$. capsici isolates. Roots of 6-weekold seedlings were inoculated with each of two $P$. capsici isolates and maintained in the greenhouse. Plants were evaluated for wilting and plant

death three times per week for 5 weeks. Significant differences were observed in disease response among the inbred tomato lines. Most lines evaluated were susceptible to $P$. capsici isolate 12889 but resistant to isolate OP97; 24 tomato lines were resistant to both isolates. Heritability of Phytophthora root rot resistance was high in this population. Polymorphic molecular markers located in genes related to resistance and defense responses were identified and added to a genetic map previously generated for the population. Resistant lines and polymorphic markers identified in this study are a valuable resource for development of tomato varieties resistant to $P$. capsici.
\end{abstract}

Phytophthora capsici Leonian is a destructive, soilborne pathogen that has a wide host range within the Solanaceae, including tomato, eggplant, and pepper (Granke et al. 2012b). In tomato (Solanum lycopersicum L.), a major vegetable crop grown in every country of the world, $P$. capsici causes root, crown, and fruit rot (Granke et al. 2012b; Quesada-Ocampo et al. 2011b). P. capsici-induced disease in tomato has been reported in several regions of the United States, including Michigan (Grube et al. 2000), California (Bolkan 1985; Critopoulos 1955; Satour and Butler 1967), and Colorado (Kreutzer et al. 1940). In recent years, the occurrence and severity of $P$. capsici infections in different crops in the United States has increased, in part, due to the use of $P$. capsici-infested water for irrigation (Hausbeck and Lamour 2004; Quesada-Ocampo et al. 2011a).

Commonly used approaches to manage $P$. capsici have included crop rotation and fungicide applications. The success of crop rotation is limited by the long-term survival of oospores in the soil and an increasing list of susceptible hosts (Gevens et al. 2008; Kousik et al. 2015; Quesada-Ocampo et al. 2009). Similarly, applications of the commonly used fungicide mefenoxam may not provide adequate control due to resistance in $P$. capsici populations throughout the United States (Quesada-Ocampo et al. 2011b). In the United States, tomato fruit are grown for the fresh-market and processing industry. Fresh-market tomato are grown using raised beds, plastic mulch, and

Corresponding author: L. M. Quesada-Ocampo;

E-mail: 1mquesad@ncsu.edu.

This material is based upon work supported by the United States Department of Agriculture (USDA) Cooperative State Research, Education and Extension Service (CSREES) Specialty Crop Research Initiative under Award Number 200851180-0488, the USDA CSREES Special Grant Research under Award Number 2008-34572-193, and the North Carolina State University Hatch Project NC02418.

*The $\boldsymbol{e}$-Xtra logo stands for "electronic extra" and indicates that two supplementary tables are published online.

Accepted for publication 29 November 2015.

http://dx.doi.org/10.1094/PDIS-08-15-0888-RE

(C) 2016 The American Phytopathological Society trellising that reduce the risk of $P$. capsici root and crown rot due to poor water drainage and the risk of fruit rot due to splashing or direct contact with the soil. In contrast, the production system of processing tomato, harvested mechanically, uses lower beds where water drainage may not be optimal and no mulch, so that fruit are in direct contact with the soil. Although disease caused by $P$. capsici is not a significant challenge in fresh-market tomato production, processing tomato growers have experienced severe losses when inoculum is available and weather conditions have been warm and wet. With the lack of affordable and dependable chemical control measures and limitations of cultural control strategies, developing resistant varieties is desirable. However, little is known about resistance to $P$. capsici in cultivated tomato (Quesada-Ocampo and Hausbeck 2010).

The limited genetic diversity following domestication in cultivated tomato has led researchers to use wild tomato species as sources of disease resistance (Rick and Yoder 1988). One example is S. habrochaites, a wild tomato that has been used to produce $\mathrm{F}_{1}$ interspecific hybrids, backcrosses $\left(\mathrm{BC}_{1}\right)$, and advanced backcrosses $\left(\mathrm{BC}_{2}\right)$ used in tomato breeding programs (Kabelka et al. 2002). Developing diseaseresistant tomato cultivars by introgression of resistance genes from wild relatives has provided effective disease control for some tomato diseases (Finkers et al. 2007). In recent studies, S. habrochaites accession LA407 showed resistance to four $P$. capsici isolates from cucurbitaceous and solanaceous crops (Quesada-Ocampo and Hausbeck 2010). Nonetheless, segregating tomato populations derived from wild relatives have not been evaluated for resistance to $P$. capsici to assess their potential for tomato improvement. In addition, available populations that have been evaluated for disease resistance to other tomato pathogens have limited molecular markers available to establish marker-trait associations (Kabelka et al. 2002). Such associations can be used for marker-assisted selection, allowing plant breeders to more quickly identify varieties with desirable agricultural traits (Robert et al. 2001). In this study, we aimed to evaluate a tomato breeding population as a genetic resource for crown and root rot resistance caused by $P$. capsici. The population includes 62 lines of a tomato inbred advanced backcross (IBC) population $\left(\mathrm{IBC}_{2} \mathrm{~S}_{4}\right)$ developed by crossing S. habrochaites accession LA407 to S. lycopersicum 'Hunt100' and 'Peto 95-43', two cultivated accessions with characteristics of contemporary processing varieties (Kabelka et al. 2002). A genetic map has 
also been generated for this tomato population that could facilitate breeding for traits such as disease resistance (Kabelka et al. 2002). Specifically, we sought to (i) determine which lines of the backcross are resistant to $P$. capsici and the heritability of the trait, (ii) add markers related to disease resistance and defense responses to the genetic map of the backcross population, and (iii) investigate associations between introgressions from the wild parent and resistance to P. capsici.

\section{Materials and Methods}

Plant material. A segregating population consisting of 62 homozygous lines was used in this study (Table 1). The LA407 IBC population consists of $62 \mathrm{BC}_{2} \mathrm{~S}_{4}$ lines developed by crossing $S$. habrochaites LA407 to $S$. lycopersicum Hunt100 (LA3144) followed by a backcross to Hunt100 (Francis et al. 2001). Individual $\mathrm{BC}_{1}$ lines were then crossed to Peto 95-43 (LA3528); $\mathrm{BC}_{2}$ lines were then advanced by self-fertilization and single-seed descent for four generations (Francis et al. 2001). Each line in the LA407 IBC population has a theoretical S. lycopersicum contribution of $87.5 \%$ and random introgressions from LA407 accounting for $12.5 \%$ (Kabelka et al. 2002).

Seed of the 62 inbred lines and the parents LA407 and LA3144 were treated with $2.7 \%$ sodium hypochlorite for $30 \mathrm{~min}$, rinsed with sterile water, and immediately sown on 72-square cell plastic flats (Hummert International, Earth City, MO) containing soilless medium (Baccto Professional Planting Mix; Michigan Peat Company, Houston) and a top layer of medium-grade vermiculite (Hummert International). Seedlings were grown for 4 weeks in a greenhouse under approximately $14 \mathrm{~h} /$ day illumination and transplanted into 2.5-liter square plastic pots (Hummert International) containing the same soilless medium described above. Plants were allowed to recover from transplant stress for 2 weeks prior to being inoculated with millet seed infested with one of two different $P$. capsici isolates and a control inoculum consisting of uninfested millet seed. For the duration of the experiment, plants were fertilized weekly with Peter's 20-20-20 water-soluble fertilizer (The Scotts Company, Marysville, $\mathrm{OH})$ and irrigated as needed.

Isolate selection and maintenance. $P$. capsici isolates that were obtained from infected cucurbit and solanaceous crops in Michigan were selected for evaluations. Isolate OP97 (A1 mating type [MT]), from pickling cucumber, is sensitive to mefenoxam, whereas isolate 12889 (A1 MT) from pepper, is insensitive. Isolates were phenotypically characterized for MT, sensitivity to mefenoxam (QuesadaOcampo et al. 2009), morphology (Granke et al. 2011), virulence (Granke et al. 2012a), and genetic identity (Quesada-Ocampo et al. 2011b) in previous studies.

Actively growing, single-spore cultures were propagated on unclarified V8 agar (UCV8A; $3 \mathrm{~g}$ of $\mathrm{CaCO}_{3}, 15 \mathrm{~g}$ of agar, $160 \mathrm{ml}$ of unfiltered V8 juice, and $840 \mathrm{ml}$ of distilled water) following longterm storage as stock cultures and activated by reinoculation and reisolation from cucumber fruit to maintain virulence, as previously described (Quesada-Ocampo et al. 2009).

Inoculum preparation and root inoculation. $P$. capsici-infested millet seed (100 g of millet seed, $0.08 \mathrm{~g}$ of asparagine, and $72 \mathrm{ml}$ of water) was prepared as previously described (Quesada-Ocampo and Hausbeck 2010). Plants were inoculated by mixing $1 \mathrm{~g}$ of millet seed infested with one of the two P. capsici isolates (OP97 or 12889) with approximately $10 \mathrm{~g}$ of soilless medium that was removed from the area adjacent to each plant stem. For each isolate, 10 replicate plants were used. Ten additional control plants were inoculated with millet seed containing sterile UCV8 plugs. The entire experiment was replicated three times.

Resistance screening. Disease assessment was conducted three times per week for 5 weeks and was initiated 2 days following inoculation on each line and parents. Disease progression was recorded for each plant as percent wilting, as previously described (QuesadaOcampo and Hausbeck 2010). The area under the disease progress curve (AUDPC) was calculated using percent wilting values and data followed assumptions for statistical analyses. The experiment was designed as a split-plot, with whole plots arranged in a randomized complete block design. Because no differences were detected among the three experiments, combined data were subjected to analysis of variance using the PROC MIXED and PROC GLIMMIX procedures of SAS (SAS Institute Inc., Cary, NC), and multiple comparisons among the means were conducted using Tukey's test when effects were found to be statistically significant at $P<0.05$. Plants were considered resistant to an isolate of $P$. capsici when their AUDPC value was lower than or not significantly different from the value of the resistant parent LA407.

Plant DNA extraction and purification. DNA was extracted from three young healthy leaves of each line and parent using the DNeasy plant mini kit, following the manufacturer's instructions (Qiagen, Valencia, CA). The DNA concentration for each sample was determined using a NanoDrop 100 spectrophotometer and the NanoDrop software (ver. 2.4.7c; Nano-Drop Technologies Inc., Wilmington, DE). A genomic DNA concentration of $15 \mathrm{ng} / \mu \mathrm{l}$ was used for amplification of simple sequence repeats (SSR) and resistance gene analogs for single-nucleotide polymorphism (SNP) detection, while $100 \mathrm{ng} / \mu \mathrm{l}$ was used to obtain amplified fragment length polymorphisms (AFLP).

Molecular markers. To map additional markers to a previously published linkage map of the tomato population (Kabelka et al. 2002), four different types of markers were tested for polymorphism: 70 AFLP, 63 restriction fragment length polymorphism (RFLP) (Francis et al. 2001), 64 SNP (Supplementary Table S1), and 106 SSR (Supplementary Table S2). All molecular markers were first tested in the parents to confirm polymorphism between them. After parent evaluations, all AFLP, SNP, and SSR without polymorphism were discarded for progeny evaluations. The RFLP analysis for the tomato population was previously published (Kabelka et al. 2002) and the data were used to generate a framework map to add the markers genotyped in this study.

AFLP analysis. Approximately $500 \mathrm{ng}$ of DNA was used with the AFLP kit for regular plant genomes (Applied Biosystems, Foster City, CA), according to the manufacturer's instructions. After preselective amplification, MseI CAC-EcoRI ACA, MseI CAG-EcoRI AAG, $M s e$ I CAC-EcoRI AAG, $M s e$ I CAA-EcoRI AAC, $M s e$ I CAA-EcoRI AAG, MseI CAC-EcoRI AAC, and MseI CAA-EcoRI ACA primer combinations were chosen for selective polymerase chain reaction (PCR). Labeled products, with a size equal to or larger than $70 \mathrm{bp}$ and with a fluorescence signal equal to or higher than 300 relative fluorescence units in at least one parent, were scored using the Peak Scanner software (ver. v1.0; Applied Biosystems).

SNP analysis. Transcripts shared by S. habrochaites (LA1777) and S. lycopersicum (TA496), annotated as resistance or defense genes and containing SNP, were identified in release 161a of the Solanaceae Genomics Resource (http://solanaceae.plantbiology. msu.edu/) and selected for primer design using Primer 3 v.0.4.0 (Rozen and Skaletsky 2000). In total, 64 pairs of primers were designed to amplify a product with an SNP located approximately in the middle of the fragment. Transcripts were amplified and sequenced in LA407 and Hunt100 to confirm SNP. Restriction enzymes that selectively digested at the SNP site in one parent but not the other were identified with CLC DNA workbench software (v5.7.1; CLC Bio, Cambridge, MA). Briefly, each PCR was performed in a $15-\mu 1$ volume consisting of $10 \mu \mathrm{M}$ each dNTP, $2.5 \mathrm{mM} \mathrm{MgCl}_{2}, 0.5 \mathrm{U}$ of Taq DNA polymerase (Promega Corp., Madison, WI), $3 \mu \mathrm{l}$ of $10 \times$ buffer, $0.4 \mu \mathrm{M}$ each primer, and $15 \mathrm{ng}$ of genomic DNA that was used as a template. The enzyme digestion was performed in a $15-\mu l$ volume with $4.5 \mu \mathrm{l}$ of PCR product, $1 \times$ enzyme buffer, $1 \times$ bovine serum albumen, and $1 \mathrm{U}$ of restriction enzyme (New England Biolabs, Ipswich, MA). The PCR program was $5 \mathrm{~min}$ at $94^{\circ} \mathrm{C}$ for an initial denaturation; 35 cycles of $30 \mathrm{~s}$ at $94^{\circ} \mathrm{C}, 45 \mathrm{~s}$ at 50 to $57^{\circ} \mathrm{C}$. and $45 \mathrm{~s}$ at $72^{\circ} \mathrm{C}$; followed by a final extension at $72^{\circ} \mathrm{C}$ by $5 \mathrm{~min}$. Digestions were performed for $1 \mathrm{~h}$ at $37^{\circ} \mathrm{C}$ and $5 \mathrm{~min}$ at $10^{\circ} \mathrm{C}$. Digested products were evaluated in high-resolution 2\% metaphor agarose gels (Lonza, Rockland, ME) and scored in the parents and progeny as present or absent.

SSR analysis. S. habrochaites and S. lycopersicum transcripts annotated as resistance or defense genes and containing SSR were identified in release 161a of the Solanaceae Genomics Resource and selected for primer design using Primer 3. Nine SSR derived from expressed sequence tags of Capsicum annuum and obtained at the 
Table 1. Mean area under the disease progress curve (AUDPC) values, percent death, disease reaction, and LA407 introgression percentage of each $\mathrm{IBC}_{2} \mathrm{~S}_{4}$ line evaluated for resistance to Phytophthora capsici

\begin{tabular}{|c|c|c|c|c|c|c|c|}
\hline \multirow[b]{2}{*}{ ID $^{\mathbf{z}}$} & \multicolumn{2}{|c|}{ Mean AUDPC } & \multicolumn{2}{|c|}{ Death $(\%)$} & \multicolumn{2}{|c|}{$\mathbf{D R}^{\mathbf{y}}$} & \multirow[b]{2}{*}{ LA407 (\%) } \\
\hline & 12889 & OP97 & 12889 & OP97 & 12889 & OP97 & \\
\hline LA407 & 13.6 wxyzABCD & $8.8 \mathrm{DE}$ & 10.5 & 6.8 & $\mathrm{R}$ & $\mathrm{R}$ & $\ldots$ \\
\hline HUNT100 & $95.7 \mathrm{ab}$ & 71.2 hijkl & 73.6 & 54.7 & S & $\mathrm{S}$ & $\ldots$ \\
\hline 2304 & $32.2 \mathrm{pq}$ & 12.9 yzABCD & 24.7 & 10.0 & $\mathrm{~S}$ & $\mathrm{R}$ & 14.1 \\
\hline 2305 & $31.5 \mathrm{pqr}$ & 12.5 yzABCD & 24.2 & 9.6 & $\mathrm{~S}$ & $\mathrm{R}$ & 11.2 \\
\hline 2306 & 15.8 vwxyzABCD & 13.0 xyzABCD & 20.0 & 12.2 & $\mathrm{R}$ & $\mathrm{R}$ & 14.6 \\
\hline 2307 & $30.8 \mathrm{pqrs}$ & 21.0 qrstuvwxyzABC & 23.7 & 16.2 & $\mathrm{~S}$ & $\mathrm{~S}$ & 28.4 \\
\hline 2309 & 20.3 rstuvwxyzABCD & $0.0 \mathrm{E}$ & 15.6 & 0.0 & $\mathrm{R}$ & $\mathrm{R}$ & 22.8 \\
\hline 2310 & 83.6 cdefg & 13.2 wxyzABCD & 64.3 & 10.1 & $\mathrm{~S}$ & $\mathrm{R}$ & 18.6 \\
\hline 2311 & 13.4 wxyzABCD & 12.1 ABCD & 10.3 & 9.3 & $\mathrm{R}$ & $\mathrm{R}$ & 26.6 \\
\hline 2313 & $60.6 \mathrm{lmn}$ & $0.0 \mathrm{E}$ & 46.6 & 0.0 & $\mathrm{~S}$ & $\mathrm{R}$ & 1.4 \\
\hline 2314 & $62.1 \mathrm{klmn}$ & $0.0 \mathrm{E}$ & 47.7 & 0.0 & $\mathrm{~S}$ & $\mathrm{R}$ & 6.7 \\
\hline 2315 & 79.9 cdefgh & $0.0 \mathrm{E}$ & 61.5 & 0.0 & $\mathrm{~S}$ & $\mathrm{R}$ & 13.5 \\
\hline 2316 & 83.3 cdefg & $0.0 \mathrm{E}$ & 64.1 & 0.0 & $\mathrm{~S}$ & $\mathrm{R}$ & 5.7 \\
\hline 2317 & $99.4 \mathrm{a}$ & $56.2 \mathrm{mno}$ & 76.5 & 43.2 & $\mathrm{~S}$ & $\mathrm{~S}$ & 8.2 \\
\hline 2318 & $0.0 \mathrm{E}$ & $0.0 \mathrm{E}$ & 0.0 & 0.0 & $\mathrm{R}$ & $\mathrm{R}$ & 14.2 \\
\hline 2319 & $0.0 \mathrm{E}$ & $0.0 \mathrm{E}$ & 0.0 & 0.0 & $\mathrm{R}$ & $\mathrm{R}$ & 14.5 \\
\hline 2321 & $91.5 a b c$ & 20.8 qrstuvwxyzABC & 70.4 & 16.0 & $\mathrm{~S}$ & $\mathrm{~S}$ & 9.7 \\
\hline 2322 & $60.3 \mathrm{lmn}$ & 14.9 vwxyzABCD & 46.4 & 11.5 & $\mathrm{~S}$ & $\mathrm{R}$ & 18.3 \\
\hline 2323 & 26.6 pqrstuv & $0.0 \mathrm{E}$ & 20.4 & 0.0 & $\mathrm{~S}$ & $\mathrm{R}$ & 23.7 \\
\hline 2325 & 74.3 fghij & $0.0 \mathrm{E}$ & 57.1 & 0.0 & $\mathrm{~S}$ & $\mathrm{R}$ & 6.9 \\
\hline 2326 & $33.4 \mathrm{p}$ & $0.0 \mathrm{E}$ & 25.7 & 0.0 & $\mathrm{~S}$ & $\mathrm{R}$ & 15.7 \\
\hline 2327 & 86.7 bcde & 24.8 pqrstuvw & 66.7 & 79.1 & $\mathrm{~S}$ & $\mathrm{~S}$ & 14.1 \\
\hline 2328 & 11.8 ABCDE & $0.0 \mathrm{E}$ & 9.1 & 0.0 & $\mathrm{R}$ & $\mathrm{R}$ & 12.9 \\
\hline 2330 & 85.4 bcdef & $0.0 \mathrm{E}$ & 65.7 & 0.0 & $\mathrm{~S}$ & $\mathrm{R}$ & 17.4 \\
\hline 2331 & 23.2 pqrstuvwxyzA & $0.0 \mathrm{E}$ & 17.9 & 0.0 & $\mathrm{R}$ & $\mathrm{R}$ & 11.3 \\
\hline 2332 & 14.1 ABCD & 10.9 BCDE & 12.3 & 8.4 & $\mathrm{R}$ & $\mathrm{R}$ & 5.9 \\
\hline 2333 & 14.6 wxyzABCD & $0.0 \mathrm{E}$ & 11.2 & 0.0 & $\mathrm{R}$ & $\mathrm{R}$ & 16.6 \\
\hline 2334 & 19.9 rstuvwxyzABCD & 17.1 uvwxyzABCD & 15.3 & 13.1 & $\mathrm{R}$ & $\mathrm{R}$ & 13.4 \\
\hline 2335 & 13.9 wxyzABCD & 21.3 qrstuvwxyzABC & 10.7 & 16.4 & $\mathrm{R}$ & $\mathrm{S}$ & 8.6 \\
\hline 2336 & 30.7 pqrst & $0.0 \mathrm{E}$ & 23.6 & 0.0 & $\mathrm{~S}$ & $\mathrm{R}$ & 10.5 \\
\hline 2337 & 62.9 jklmn & 24.0 pqrstuvwxyz & 48.4 & 18.5 & $\mathrm{~S}$ & $\mathrm{~S}$ & 3.9 \\
\hline 2338 & 12.4 yzABCD & $0.0 \mathrm{E}$ & 9.6 & 0.0 & $\mathrm{R}$ & $\mathrm{R}$ & 22.5 \\
\hline 2339 & 13.7 wxyzABCD & 14.9 vwxyzABCD & 10.6 & 11.5 & $\mathrm{R}$ & $\mathrm{R}$ & 12.2 \\
\hline 2340 & 82.6 cdefgh & 19.5 stuvwxyzABCD & 63.5 & 15.0 & $\mathrm{~S}$ & $\mathrm{R}$ & 15.1 \\
\hline 2341 & 12.3 yzABCD & $0.0 \mathrm{E}$ & 9.5 & 0.0 & $\mathrm{R}$ & $\mathrm{R}$ & 14.1 \\
\hline 2342 & 22.2 pqrstuvwxyzAB & $0.0 \mathrm{E}$ & 17.1 & 0.0 & $\mathrm{R}$ & $\mathrm{R}$ & 15.2 \\
\hline 2343 & 70.8 hijkl & 12.5 yzABCD & 54.4 & 9.6 & $\mathrm{~S}$ & $\mathrm{R}$ & 22.4 \\
\hline 2344 & 89.4 abcd & $9.9 \mathrm{CDE}$ & 68.8 & 7.6 & $\mathrm{~S}$ & $\mathrm{R}$ & 15.6 \\
\hline 2345 & 52.0 no & $0.0 \mathrm{E}$ & 40.0 & 0.0 & $\mathrm{~S}$ & $\mathrm{R}$ & 9.2 \\
\hline 2346 & 90.8 abcd & 72.4 ghijk & 69.8 & 55.7 & $\mathrm{~S}$ & $\mathrm{~S}$ & 8.3 \\
\hline 2347 & $0.0 \mathrm{E}$ & $0.0 \mathrm{E}$ & 0.0 & 0.0 & $\mathrm{R}$ & $\mathrm{R}$ & 16.1 \\
\hline 2348 & 89.3 abcd & 79.3 defgh & 68.7 & 61.0 & $\mathrm{~S}$ & $\mathrm{~S}$ & 11.9 \\
\hline 2349 & 73.1 ghijk & 17.9 uvwxyzABCD & 56.2 & 13.8 & $\mathrm{~S}$ & $\mathrm{R}$ & 8.1 \\
\hline 2350 & 21.8 pqrstuvwxyzAB & $0.0 \mathrm{E}$ & 16.8 & 0.0 & $\mathrm{R}$ & $\mathrm{R}$ & 10.7 \\
\hline 2351 & 17.7 uvwxyzABCD & $0.0 \mathrm{E}$ & 13.6 & 0.0 & $\mathrm{R}$ & $\mathrm{R}$ & 12.5 \\
\hline 2352 & 88.9 abcd & 13.7 wxyzABCD & 68.4 & 10.5 & $\mathrm{~S}$ & $\mathrm{R}$ & 8.4 \\
\hline 2353 & $0.0 \mathrm{E}$ & $0.0 \mathrm{E}$ & 0.0 & 0.0 & $\mathrm{R}$ & $\mathrm{R}$ & 10.3 \\
\hline 2354 & 75.3 efghi & $10.8 \mathrm{BCDE}$ & 57.9 & 8.3 & $\mathrm{~S}$ & $\mathrm{R}$ & 5.6 \\
\hline 2355 & $18.9 \mathrm{zABCD}$ & 12.3 tuvwxyzABCD & 14.6 & 9.4 & $\mathrm{R}$ & $\mathrm{R}$ & 5.7 \\
\hline 2356 & 16.4 vwxyzABCD & $0.0 \mathrm{E}$ & 12.6 & 0.0 & $\mathrm{R}$ & $\mathrm{R}$ & 23.4 \\
\hline 2357 & 24.1 pqrstuvwxy & $0.0 \mathrm{E}$ & 18.5 & 0.0 & $\mathrm{R}$ & $\mathrm{R}$ & 9.6 \\
\hline 2358 & 46.9 o & 23.6 pqrstuvwxyzA & 36.1 & 18.1 & $\mathrm{~S}$ & $\mathrm{~S}$ & 12.0 \\
\hline 2359 & $32.3 \mathrm{pq}$ & 20.5 qrstuvwxyzABCD & 24.8 & 15.8 & $\mathrm{~S}$ & $\mathrm{R}$ & 11.1 \\
\hline 2360 & 48.3 o & $0.0 \mathrm{E}$ & 37.2 & 0.0 & $\mathrm{~S}$ & $\mathrm{R}$ & 13.4 \\
\hline 2361 & $0.0 \mathrm{E}$ & $0.0 \mathrm{E}$ & 0.0 & 0.0 & $\mathrm{R}$ & $\mathrm{R}$ & 14.4 \\
\hline 2362 & 21.2 qrstuvwxyzABC & 24.8 pqrstuvwx & 16.3 & 19.1 & $\mathrm{R}$ & $\mathrm{S}$ & 12.2 \\
\hline 2363 & $0.0 \mathrm{E}$ & $0.0 \mathrm{E}$ & 0.0 & 0.0 & $\mathrm{R}$ & $\mathrm{R}$ & 13.6 \\
\hline 2364 & $55.9 \mathrm{mno}$ & 17.7 uvwxyzABCD & 43.0 & 13.6 & $\mathrm{~S}$ & $\mathrm{R}$ & 18.3 \\
\hline 2365 & 71.2 hijkl & 13.7 wxyzABCD & 54.8 & 10.6 & $\mathrm{~S}$ & $\mathrm{R}$ & 32.3 \\
\hline 2366 & 16.8 uvwxyzABCD & 21.2 qrstuvwxyzABC & 12.9 & 16.3 & $\mathrm{R}$ & $\mathrm{S}$ & 11.1 \\
\hline 2367 & 28.3 pqrstu & 21.2 qrstuvwxyzABC & 21.8 & 16.3 & $\mathrm{~S}$ & $\mathrm{~S}$ & 10.1 \\
\hline 2368 & 66.7 ijklm & 16.3 vwxyzABCD & 51.3 & 12.5 & $\mathrm{~S}$ & $\mathrm{R}$ & 22.1 \\
\hline 2369 & 81.9 cdefgh & $0.0 \mathrm{E}$ & 63.0 & 0.0 & $\mathrm{~S}$ & $\mathrm{R}$ & 14.6 \\
\hline 2370 & $13.2 \mathrm{E}$ & 0.0 wxyzABCD & 10.1 & 0.0 & $\mathrm{R}$ & $\mathrm{R}$ & 25.9 \\
\hline
\end{tabular}

${ }^{x}$ Mean AUDPC values for each isolate followed by the same letter are not significantly different.

y Disease reaction (DR): lines with no significant differences in mean AUDPC values with LA407 or with lower mean AUDPC values were considered resistant (R) and all other lines were considered susceptible (S).

z Genotype identification number. 
Sol Genomics Network website (https://solgenomics.net/) were also included for primer design using Primer 3. PCR assays were performed as described above. Products were evaluated in high-resolution $3 \%$ metaphor agarose gels (Lonza) and scored in the parents and progeny as present or absent.

Heritability analysis and genetic map construction. Heritability for resistance to each isolate was estimated using the mean squares implemented within a formula previously described (Fehr 1987). For disease data, the experimental repetitions were treated as a single location with multiple dates. Confidence intervals (CI) were calculated as previously described (Knapp et al. 1985). Linkage groups were generated using 152 polymorphic markers (63 RFLP, 48 AFLP, 20 SSR, and 21 SNP), a linkage criterion of $P=0.05$, and the Kosambi mapping function with the software Map Manager QTXb20.1 (Manly et al. 2001). Local permutations of the order of markers within a chromosome (ripple function) were performed to find the best distance between loci. The informative loci, genotype frequencies, number of crossovers, map distance, confidence limit (low and high according with the $95 \%$ CI for map distance), log of the odds (LOD) for linkage, and coverage in centimorgans were determined for each locus within a chromosome. Quantitative trait loci (QTL) analyses were not performed due to the limited size of the tomato population.

Introgression analysis. The program STRUCTURE (version 2.3.4) (Pritchard et al. 2000) was used for backcross introgression analysis using all available markers for the population. The analysis was performed using linked loci correlations on each chromosome, with the ancestry linkage model and correlated allele frequencies (Falush et al. 2003). This option uses the admixture model and takes into account the linkage disequilibrium between chromosomes. Several analyses were performed with different combinations of burn-in values $(50,000$ to 200,000), Markov chain Monte Carlo (MCMC) chains (50,000 to $100,000)$, values of $K$ from 1 to 5 , and $\lambda=1$ using the 62 tomato lines and parents $(n=64)$, with all loci genotyped $(l=152)$ and grouped by each of the 12 tomato chromosomes. After preliminary analyses, the burn-in value was set to 100,000 , the MCMC chains to 100,000 , the $\lambda$ to 1 , and the $K$ value with the highest likelihood was determined to be $\mathrm{K}=2$. Using the linkage model, the LA407 or S. lycopersicum genetic cluster content per chromosome in each tomato line and the parents was determined. The clustering quality as a function of number of markers per chromosome was also established. The parameters used for this analysis were the same as for the previous analysis. When the fixation index (Fst) value had a symmetrical distribution at a specific K, the assumption was that the data did not have structure and, consequently, did not provide information about the introgressions per chromosome.

\section{Results}

An advanced backcross $\left(\mathrm{BC}_{2} \mathrm{~S}_{4}\right)$ population $(n=62)$ was used to determine the resistance to $P$. capsici for each line (Table 1 ). As observed in previous studies (Quesada-Ocampo and Hausbeck 2010), disease symptoms in susceptible lines were observed 4 to 5 days postinoculation whereas resistant lines did not present any disease symptoms or symptoms were significantly delayed compared with susceptible ones. Symptoms included ascending wilt and chlorosis, root and crown rot, cankers at the crown that progressed upward along the stem, and stunting. When the crown rot and cankers were severe in the most susceptible lines, the base of the plant collapsed, resulting in rapid wilting of the canopy and death of the plant. Some tolerant lines were able to rapidly generate secondary roots above rotted areas of the crown, which allowed them to maintain healthy canopies and recover from disease.

AUDPC values were significantly different among tomato lines and between isolates $(P<0.01)$. In all, 24 lines were found to be resistant to both $P$. capsici isolates OP97 and 12889, 27 lines were resistant to isolate 12889 , and 50 lines were resistant to isolate OP97 (Table 1). Lines 2335, 2362, and 2366 were resistant to $P$. capsici isolate 12889 but susceptible to isolate OP97 (Table 1). Additionally, AUDPC values of lines 2318, 2319, 2347, 2353, 2361, 2363, and 2370 showed significant differences from LA407 in disease response after inoculation with 12889 , due to a lower AUDPC value (more resistant) than LA407. No lines resistant to isolate OP97 were significantly different from LA407 but 29 of the resistant lines had lower AUDPC values. Interestingly, AUDPC values of resistant lines $2318,2319,2347,2353,2361$, and 2363 were lower than LA407 when inoculated with each of the two isolates (Table 1). Additionally, 12 lines resistant to OP97 showed lower AUDPC values than LA407 but had higher AUDPC values and were significantly more susceptible than LA407 when challenged with isolate 12889 . The lines that were susceptible to $P$. capsici 12889 but resistant to OP97 were 2313, 2314, 2315, 2316, 2323, 2325, 2326, 2330, 2336, 2345, 2360, and 2369 (Table 1). Lines 2307, 2317, 2321, 2327, 2337, 2346, 2348, 2358, and 2367 were susceptible to both $P$. capsici isolates (Table 1 ). In susceptible lines for one or both of the $P$. capsici isolates, mild wilting was evident 4 days after inoculation and symptoms progressed as previously described (Quesada-Ocampo and Hausbeck 2010). Symptoms caused by $P$. capsici isolate 12889 were more severe and progressed faster than in plants inoculated with OP97. The resistant parent LA407 and other resistant lines showed a very mild level of wilting 10 or more days after inoculation and subsequently recovered.

Broad sense heritability $(\mathrm{H})$ in this population was high for Phytophthora root rot resistance to isolates $12889(\mathrm{H}=0.95, \mathrm{CI}=0.92$ to 0.96$)$ and $\mathrm{OP} 97(\mathrm{H}=0.98, \mathrm{CI}=0.97$ to 0.98$)$. The 62 lines from the $\mathrm{IBC}_{2} \mathrm{~S}_{4}$ population were used to generate a genetic map and locate additional markers that could be used in future breeding efforts. After evaluating 301 molecular markers, approximately half of the markers (152 markers) had polymorphism between the parents and showed segregation in the progeny. Polymorphic and segregating markers included 63 framework RFLP markers, 48 AFLP (three primer combinations: MseI CAC-EcoRI ACA, MseI CAG-EcoRI AAG, and MseI CAC-EcoRI AAG), 20 SSR, and 21 SNP. The genetic map covered 1,099 centimorgans $(\mathrm{cM})$ and included 12 linkage groups that corresponded to the 12 tomato chromosomes using a recombination fraction

Table 2. Tomato linkage groups for $\mathrm{IBC}_{2} \mathrm{~S}_{4} \mathrm{LA} 407 \times \mathrm{Hunt} 100^{\mathrm{z}}$

\begin{tabular}{|c|c|c|c|c|c|c|c|c|c|c|}
\hline $\begin{array}{l}\text { Linkage } \\
\text { group }\end{array}$ & Length (cM) & $\begin{array}{c}\text { Number of } \\
\text { markers }\end{array}$ & RFLP & AFLP & SSR & SNP & $\begin{array}{c}\text { Average } \\
\text { spacing }(\mathbf{c M})\end{array}$ & $\begin{array}{c}\text { Largest } \\
\text { distance }(\mathrm{cM})\end{array}$ & LOD & $\begin{array}{c}\text { Recombination } \\
\text { fraction }(\mathbf{Q})\end{array}$ \\
\hline Chr1 & 127.2 & 22 & 7 & 12 & 1 & 2 & 5.5 & 17 & $3.23-18.06$ & $0.02-0.17$ \\
\hline $\mathrm{Chr} 2$ & 120.4 & 13 & 6 & 1 & 4 & 2 & 9.3 & 20.8 & $3-18.66$ & $0.02-0.26$ \\
\hline Chr3 & 132.7 & 23 & 7 & 5 & 7 & 4 & 6.0 & 13.5 & $3.29-18.36$ & $0.02-0.27$ \\
\hline Chr4 & 149 & 29 & 6 & 19 & 0 & 4 & 5.1 & 10.9 & $3.29-18.36$ & $0.02-0.29$ \\
\hline Chr5 & 68.8 & 10 & 4 & 1 & 4 & 1 & 6.9 & 11.5 & $3.91-18.66$ & $0.02-0.29$ \\
\hline Chr6 & 73.1 & 9 & 5 & 0 & 2 & 2 & 8.1 & 15.2 & $3.29-18.36$ & $0.02-0.26$ \\
\hline Chr7 & 83.3 & 8 & 5 & 0 & 1 & 2 & 10.4 & 17.9 & $3.54-11.68$ & $0.02-0.24$ \\
\hline Chr8 & 75.2 & 6 & 6 & 0 & 0 & 0 & 12.5 & 27 & $6.32-18.36$ & $0.01-0.17$ \\
\hline Chr9 & 41.1 & 3 & 3 & 0 & 0 & 0 & 13.7 & 25.8 & $3.12-15.56$ & $0.02-0.26$ \\
\hline Chr10 & 80.4 & 13 & 5 & 3 & 1 & 4 & 6.2 & 11.9 & $4.42-18.66$ & $0.016-0.211$ \\
\hline Chr11 & 67.4 & 11 & 4 & 7 & 0 & 0 & 6.1 & 11.7 & $3.77-14.25$ & $0.033-0.24$ \\
\hline Chr12 & 80.4 & 5 & 5 & 0 & 0 & 0 & 16.1 & 28 & $4.25-13.40$ & $0.02-0.23$ \\
\hline Total & 1,099 & 152 & 63 & 48 & 20 & 21 & $\ldots$ & $\ldots$ & $\ldots$ & $\ldots$ \\
\hline
\end{tabular}

${ }^{\mathrm{z}}$ Abbreviations: $\mathrm{cM}=$ centimorgans, RFLP $=$ restriction fragment length polymorphism, AFLP $=$ amplified fragment length polymorphism, $\mathrm{SSR}=$ simple sequence repeats, $\mathrm{SNP}=$ single-nucleotide polymorphisms, $\mathrm{LOD}=\log$ of the odds, and $\mathrm{Chr}=$ chromosome. 
from 0.016 to 0.29 and LOD of 3.0 or higher (Table 2). In total, 89 markers were added to the original linkage map previously published (Kabelka et al. 2002); of those markers, 48 constituted nonannotated markers (AFLP) but the remaining 41 markers (SSR and SNP) were located in genes with annotations related to disease resistance and defense responses. The map coverage achieved corresponds approximately to $81.4 \%$ of the total genome for an advanced backcross population (Bernacchi et al. 1998). Chromosomes 8, 9, and 12 had lower marker coverage than the remaining chromosomes, and no new markers mapped to these groups. Markers located in genes with annotations related to disease resistance and defense responses were mapped to all chromosomes except for 8, 9, 11, and 12. Markers with no annotation (AFLP) were mapped to all chromosomes except for $6,7,8,9$, and 12 .

The results obtained from the STRUCTURE analysis for each line (Fig. 1) indicated that the average percentage of the $S$. habrochaites LA407 genome in the $\mathrm{IBC}_{2} \mathrm{~S}_{4}$ progeny was $13.7 \%$, which was confirmed by performing the same analyses on individual chromosomes (data not shown). Chromosomes with low marker coverage such as 8, 9, and 12, had symmetrical Fst values in all $\mathrm{K}$ evaluations performed; nonetheless, the population structure with the data of all chromosomes combined accurately established the LA407 content. Results were consistent with the theoretical expectation of $12.5 \%$ LA407 content per line (Kabelka et al. 2002) for this advanced backcross. The percentage of the LA407 genome varied among lines. Lower values were found in the lines 2313, 2337, 2354, 2316, 2355, 2332, 2314, and 2325 with an LA407 content between 1.5 and $7 \%$ (Table 1). Higher values from 22 to $32 \%$ were observed in lines $2365,2307,2311,2370,2323,2356$, 2309, 2338, 2343, and 2368 (Table 1). No significant correlation was observed between percentage of LA407 content in the lines and resistance to either $P$. capsici isolate.

\section{Discussion}

In this study, resistance to $P$. capsici in an $\mathrm{IBC}_{2} \mathrm{~S}_{4}$ tomato population was investigated using two $P$. capsici isolates with different virulences; isolate 12889 produced a susceptible reaction on $55 \%$ of the lines, while $17 \%$ were susceptible to OP97. The phenotypic variation in resistance found in each line had a consistent relationship with the virulence of the isolate used; that is, fewer lines were resistant to the more virulent isolate $P$. capsici 12889 . Our results provide evidence for the existence of physiological races in $P$. capsici infecting tomato similar to those in pepper and eggplant (Foster et al. 2013; Naegele et al. 2014; Sy et al. 2005). Partial resistance to P. capsici physiological races has been previously reported on tomato cultivars and wild relatives, and related species (Naegele et al. 2014; Quesada-Ocampo and Hausbeck 2010). The quantitative and isolate-specific nature of the response of tomato lines to $P$. capsici infection suggests that resistance to this pathogen in tomato is polygenic, similar to resistance in pepper. Most commercial pepper varieties currently available do not show high levels of resistance to $P$. capsici due to the complex inheritance of the trait and difficulty with reproducible phenotypic screens (Naegele et al. 2014; Oelke et al. 2003; Thabuis et al. 2004). QTL for resistance to $P$. capsici have been identified in pepper using segregating populations (Lefebvre and Palloix 1996; Naegele et al. 2014; Oelke et al. 2003; Pflieger et al. 2001; Thabuis et al. 2003, 2004) but not in tomato, due to the lack of knowledge of lines with high resistance and derived segregating populations of a sufficiently large size for this type of analysis. Although, in this study, we were unable to reliably detect QTL conferring resistance to $P$. capsici in tomato due to the small size of the backcross population, we did identify several progeny that show resistance to one or both highly virulent $P$. capsici isolates and that have desirable horticultural characteristics due to their significant Hunt100 genetic background. The high heritability of Phytophthora root rot resistance further suggests that integrating resistance into commercial tomato will be possible.

Annotated markers such as SNP and SSR derived from resistance or defense-related genes can provide information to link phenotype to genotype because they represent coding regions of the genome (López et al. 2007). In this study, we developed and mapped annotated markers in a previously published tomato linkage map to evaluate their usefulness as markers for future breeding efforts. Although we did not find any annotated markers strongly associated with $P$. capsici resistance, markers representing defense-related genes segregated within the population. Evaluation of the segregation of these markers in a larger population may lead to insight into the $P$. capsici-tomato interaction.

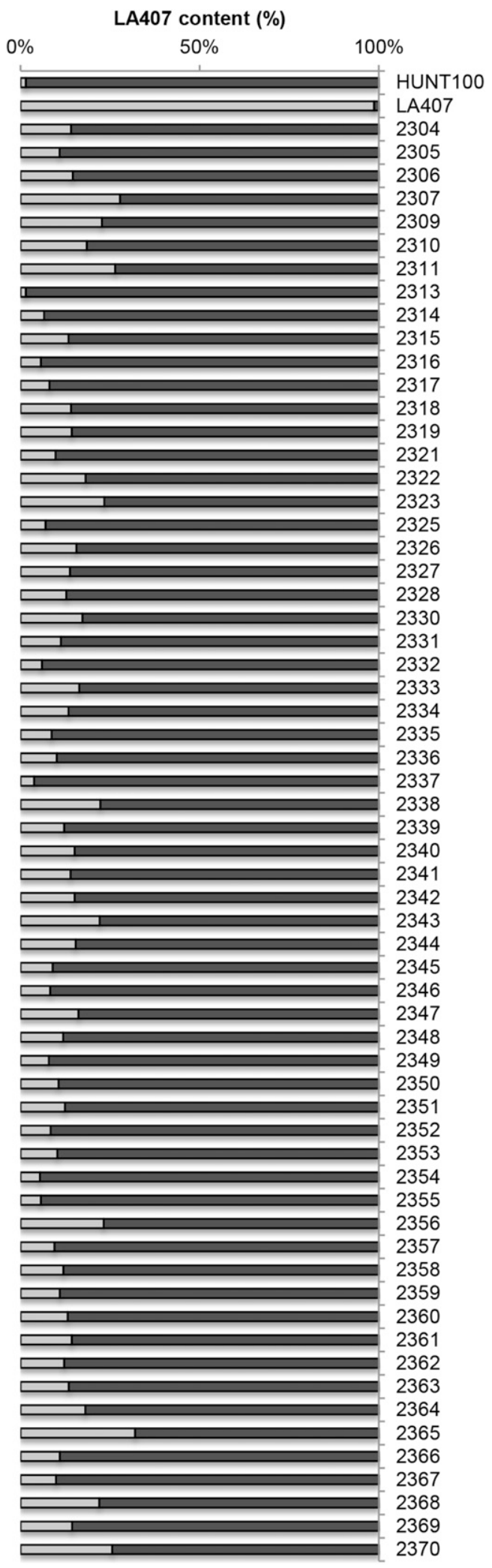

Fig. 1. LA407 and Hunt100 shared genome percentage on each line. Dark-gray zone represents genotype in common with Hunt100 (susceptible to disease caused by Phytophthora capsici) and light-gray zone represents genotype in common with LA407, the resistant parent. 
The donor $S$. habrochaites has been reported to be resistant to $P$. infestans in other studies suggesting it may have broad resistance to several Phytophthora spp. Interspecific mapping using S. habrochaites as a donor of resistance to several pathogens has identified various QTL conferring resistance to Botrytis cinerea, bacterial canker, and early blight on the same chromosome regions as the QTL found for $P$. infestans resistance (Brouwer et al. 2004; Finkers et al. 2007; Francis et al. 2001; Zhang et al. 2002, 2003). Several $P$. capsici resistance QTL have been identified on chromosomes 1, 2, and 3 using different pepper crosses (Grube et al. 2000; Lefebvre and Palloix 1996; Naegele et al. 2014; Pflieger et al. 2001; Sy et al. 2005; Thabuis et al. 2003), suggesting the possible clustering of resistance to Phytophthora spp. within the family Solanaceae.

In tomato, advanced backcross populations have been an effective method to simultaneously incorporate quality and disease resistance traits into a cultivated background while also identifying regions of the genome underlying the desired traits (Francis et al. 2001; Foolad et al. 2002; Kabelka et al. 2002; Kreutzer et al. 1940; Zhang et al. 2003). S. habrochaites is an important source of disease resistance for several tomato pathogens and, in the IBC population, the donor parent $S$. habrochaites LA407 contributed favorable alleles that were backcrossed and fixed in the progeny. This introgression varied widely among the lines, with as little as $1.5 \%$ and as much as $32 \%$ of the genome estimated to be from LA407. No correlation was observed between LA407 content and resistance to $P$. capsici, indicating that specific genomic regions have to be introgressed into a line to achieve resistance.

Lines $2311,2318,2319$, and 2341 were resistant to both $P$. capsici isolates. These lines only have one to four fragments of chromosome 3 introgressed. Also, some lines with resistance to OP97 and 12889 had specific segments introgressed on chromosomes 1 or 2 . For example, line 2338 had a specific fragment at $30 \mathrm{cM}$ on chromosome 2, line 2347 at 60 $\mathrm{cM}$ on chromosome 1 , and line 2353 at $80 \mathrm{cM}$ on chromosome 2. Lines 2322 and 2310 had a high percentage of introgression on chromosome 1 but were both susceptible to $P$. capsici isolates. Lines 2340, 2344, 2352, and 2354 were susceptible to both $P$. capsici isolates and shared specific segments on chromosome 2 located at $38 \mathrm{cM}$. Additional experiments with larger mapping populations are needed to verify whether these introgressions have a direct role in resistance or susceptibility to $P$. capsici.

This study is the first evaluation of the genetic control of Phytophthora root rot resistance in tomato. LA407, the donor parent of the IBC population, is a valuable source of economically important traits, including resistance to diverse pathogens for the improvement of cultivated tomato crops (Finkers et al. 2007; Eshed and Zamir 1995; Zhang et al. 2002, 2003). After analysis of the S. habrochaites $\times$ $S$. lycopersicon $\mathrm{IBC}_{2} \mathrm{~S}_{4}$ population, we found candidate lines with resistance to $P$. capsici and low levels of introgression of additional LA407 alleles. Molecular markers related to resistance and defense responses were also located in the genetic map of this tomato population, and will provide valuable tools for breeders incorporating resistance. These findings will be useful for disease management strategies that reduce fungicide use while decreasing losses due to disease.

\section{Acknowledgments}

We thank all the members of the Quesada lab for their valuable help; and M. Mercier, A. Lebeis, M. Wood, J. Olsen, R. Heslip, B. Webster, C. Bloomers, J. Foster, T. VanderMaas, A. Boone, and B. Harlan for technical assistance.

\section{Literature Cited}

Bernacchi, D., Beck-Bunn, T., Eshed, Y., Lopez, J., Petiard, V., Uhlig, J., Zamir, D., and Tanksley, S. 1998. Advanced backcross QTL analysis in tomato. I. Identification of QTLs for traits of agronomic importance from Lycopersicon hirsutum. Theor. Appl. Genet. 97:381-397.

Bolkan, H. A. 1985. A technique to evaluate tomatoes for resistance to Phytophthora root rot in the greenhouse. Plant Dis. 69:708-709.

Brouwer, D. J., Jones, E. S., and Clair, D. A. S. 2004. QTL analysis of quantitative resistance to Phytophthora infestans (late blight) in tomato and comparisons with potato. Genome 47:475-492.

Critopoulos, P. D. 1955. Foot rot of tomato incited by Phytophthora capsici. Bull. Torrey Bot. Club 82:168-182.

Eshed, Y., and Zamir, D. 1995. An introgression line population of Lycopersicon pennellii in the cultivated tomato enables the identification and fine mapping of yield-associated QTL. Genetics 141:1147-1162.
Falush, D., Stephens, M., and Pritchard, J. K. 2003. Inference of population structure using multilocus genotype data: Linked loci and correlated allele frequencies. Genetics 164:1567-1587.

Fehr, W. R. 1987. Principles of Cultivar Development. Macmillan, Inc., New York.

Finkers, R., van den Berg, P., van Berloo, R., ten Have, A., van Heusden, A., van Kan, J. L., and Lindhout, P. 2007. Three QTLs for Botrytis cinerea resistance in tomato. Theor. Appl. Genet. 114:585-593.

Foolad, R., Zhang, P., Khan, A. A., Nino-Liu, D., and Lin, Y. 2002. Identification of QTLs for early blight (Alternaria solani) resistance in tomato using backcross populations of a Lycopersicon esculentum $\times$ L. hirsutum cross. Theor. Appl. Genet. 104:945-958.

Foster, J. M., Naegele, R. P., and Hausbeck, M. K. 2013. Evaluation of eggplant rootstocks and pepper varieties for potential resistance to isolates of Phytophthora capsici from Michigan and New York. Plant Dis. 97:1037-1041.

Francis, D. M., Kabelka, E., Bell, J., Franchino, B., and St. Clair, D. 2001 Resistance to bacterial canker in tomato (Lycopersicon hirsutum LA407) and its progeny derived from crosses to L. esculentum. Plant Dis. 85:1171-1176.

Gevens, A. J., Donahoo, R. S., Lamour, K. H., and Hausbeck, M. K. 2008. Characterization of Phytophthora capsici causing foliar and pod blight of snap bean in Michigan. Plant Dis. 92:201-209.

Granke, L. L., Quesada-Ocampo, L. M., and Hausbeck, M. K. 2011. Variation in phenotypic characteristics of Phytophthora capsici isolates from a worldwide collection. Plant Dis. 95:1080-1088.

Granke, L. L., Quesada-Ocampo, L. M., and Hausbeck, M. K. 2012a. Differences in virulence of Phytophthora capsici isolates from a worldwide collection on host fruits. Eur. J. Plant Pathol. 132:281-296.

Granke, L. L., Quesada-Ocampo, L., Lamour, K., and Hausbeck, M. K. 2012b. Advances in research on Phytophthora capsici on vegetable crops in the United States. Plant Dis. 96:1588-1600.

Grube, R. C., Radwanski, E. R., and Jahn, M. 2000. Comparative genetics of disease resistance within the Solanaceae. Genetics 155:873-887.

Hausbeck, M. K., and Lamour, K. H. 2004. Phytophthora capsici on vegetable crops: Research progress and management challenges. Plant Dis. 88: 1292-1303

Kabelka, E., Franchino, B., and Francis, D. M. 2002. Two loci from Lycopersicon hirsutum LA407 confer resistance to strains of Clavibacter michiganensis subsp. michiganensis. Phytopathology 92:504-510.

Knapp, S. J., Stroup, W. W., and Ross, W. M. 1985. Exact confidence intervals for heritability on a progeny mean basis. Crop Sci. 25:192-194.

Kousik, C. S., Parada, C., and Quesada-Ocampo, L. M. 2015. First report of Phytophthora fruit rot on bitter gourd (Mormodica charantia) and sponge gourd (Luffa cylindrica) caused by Phytophthora capsici. Plant Health Prog. 16:93-94.

Kreutzer, W. A., Bodine, E. W., and Durrell, L. W. 1940. Cucurbit diseases and rot of tomato fruit caused by Phytophthora capsici. Phytopathology 30:972-976.

Lefebvre, V., and Palloix, A. 1996. Both epistatic and additive effects of QTLs are involved in polygenic induced resistance to disease: A case study, the interaction pepper-Phytophthora capsici Leonian. Theor. Appl. Genet. 93 503-511.

López, C. E., Quesada-Ocampo, L. M., Bohorquez, A., Duque, M. C., Vargas, J., Tohme, J., and Verdier, V. 2007. Mapping EST-derived SSRs and ESTs involved in resistance to bacterial blight in Manihot esculenta. Genome 50: 1078-1088

Manly, K. F., Cudmore, R. H., Jr., and Meer, J. M. 2001. Map Manager QTX, cross-platform software for genetic mapping. Mamm. Genome 12:930-932.

Naegele, R. P., Ashrafi, H., Hill, T. A., Chin-Wo, S. R., Van Deynze, A. E., and Hausbeck, M. K. 2014. QTL mapping of fruit rot resistance to the plant pathogen Phytophthora capsici in a recombinant inbred line Capsicum annuum population. Phytopathology 104:479-483.

Naegele, R. P., Boyle, S., Quesada-Ocampo, L. M., and Hausbeck, M. K. 2014 Genetic diversity, population structure, and resistance to Phytophthora capsici of a worldwide collection of eggplant germplasm. PLoS One 9:e95930.

Oelke, L. M., Bosland, P. W., and Steiner, R. 2003. Differentiation of race specific resistance to Phytophthora root rot and foliar blight in Capsicum annuum. J. Am. Soc. Hortic. Sci. 128:213-218.

Pflieger, S., Palloix, A., Caranta, C., Blattes, A., and Lefebvre, V. 2001. Defense response genes co-localize with quantitative disease resistance loci in pepper. Theor. Appl. Genet. 103:920-929.

Pritchard, J. K., Stephens, M., and Donnelly, P. 2000. Inference of population structure using multilocus genotype data. Genetics 155:945-959.

Quesada-Ocampo, L. M., Fulbright, D. W., and Hausbeck, M. K. 2009. Susceptibility of Fraser fir to Phytophthora capsici. Plant Dis. 93:135-141.

Quesada-Ocampo, L. M., Granke, L. L., and Hausbeck, M. K. 2011a. Temporal genetic structure of Phytophthora capsici populations from a creek used for irrigation in Michigan. Plant Dis. 95:1358-1369.

Quesada-Ocampo, L. M., Granke, L. L., Mercier, M. R., Olsen, J., and Hausbeck, M. K. 2011b. Investigating the genetic structure of Phytophthora capsici populations. Phytopathology 101:1061-1073.

Quesada-Ocampo, L. M., and Hausbeck, M. K. 2010. Resistance in tomato and wild relatives to crown and root rot caused by Phytophthora capsici. Phytopathology 100:619-627.

Rick, C. M., and Yoder, J. I. 1988. Classical and molecular genetics of tomato: Highlights and perspectives. Annu. Rev. Genet. 22:281-300. 
Robert, V. M., West, M. L., Inai, S., Caines, A., Arntzen, L., Smith, J., and St. Clair, D. 2001. Marker-assisted introgression of blackmold resistance QTL alleles from wild Lycopersicon cheesmanii to cultivated tomato (L. esculentum) and evaluation of QTL phenotypic effects. Mol. Breed. 8:217-233.

Rozen, S., and Skaletsky, H. 2000. Primer3 on the WWW for general users and for biologist programmers. Methods Mol. Biol. 132:365-386.

Satour, M. M., and Butler, E. E. 1967. A root and crown rot of tomato caused by Phytophthora capsici and Phytophthora parasitica. Phytopathology 57:510-515.

Sy, O., Bosland, P. W., and Steiner, R. 2005. Inheritance of Phytophthora stem blight resistance as compared to Phytophthora root rot and Phytophthora foliar blight resistance in Capsicum annuum L. J. Am. Soc. Hortic. Sci. 130:75-78.

Thabuis, A., Lefebvre, V., Bernard, G., Daubeze, A. M., Phaly, T., Pochard, E., and Palloix, A. 2004. Phenotypic and molecular evaluation of a recurrent selection program for a polygenic resistance to Phytophthora capsici in pepper. Theor. Appl. Genet. 109:342-351.

Thabuis, A., Palloix, A., Pflieger, S., Daubeze, A. M., Caranta, C., and Lefebvre, V. 2003. Comparative mapping of Phytophthora resistance loci in pepper germplasm: Evidence for conserved resistance loci across Solanaceae and for a large genetic diversity. Theor. Appl. Genet. 106:1473-1485.

Zhang, L. P., Khan, A., Nino-Liu, D., and Foolad, M. R. 2002. A molecular linkage map of tomato displaying chromosomal locations of resistance gene analogs based on a Lycopersicon esculentum $\times$ Lycopersicon hirsutum cross. Genome 45:133-146.

Zhang, L. P., Lin, G. Y., Nino-Liu, D., and Foolad, M. R. 2003. Mapping QTLs conferring early blight (Alternaria solani) resistance in a Lycopersicon esculentum-L. hirsutum cross by selective genotyping. Mol. Breed. 12:3-19. 